Kielmann, M.; Flanagan, K. J.; Senge, M. O. (2020):

Targeted Synthesis of Regioisomerically Pure Dodecasubstituted Type I Porphyrins through the Exploitation of Peri-interactions. The Journal of Organic Chemistry 85, 7603-7610. doi: 10.1021/acs.joc.0c00798

\title{
Targeted synthesis of regioisomerically pure dodecasubstituted type I porphyrins through the exploitation of peri-interactions
}

Marc Kielmann, Keith J. Flanagan, Mathias O. Senge*

School of Chemistry, SFI Tetrapyrrole Laboratory, Trinity Biomedical Sciences Institute, Trinity College Dublin, the University of Dublin, 152-160 Pearse St., Dublin 2, Ireland

Email: Mathias O. Senge - sengem@tcd.ie

${ }^{*}$ Corresponding author

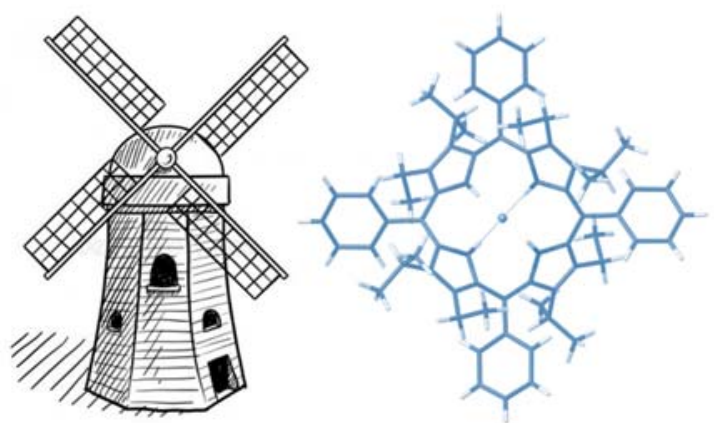

ABSTRACT: A targeted synthesis of dodecasubstituted type I porphyrins that utilizes the reaction of unsymmetrical 3,4-difunctionalized pyrroles and sterically demanding aldehydes was developed. This way, type I porphyrins could be obtained as the only type isomers, likely due to a minimization of the steric strain arising from periinteractions. Uniquely, this method does not depend on lengthy precursor syntheses, the separation of isomers, or impractical limitations of the scale. In addition, single crystal X-ray analysis elucidated the structural features of the macrocycles. 
Porphyrins are abundant in nature where they fulfill many important roles, for example, in the functioning of pigment protein complexes and metalloproteins. ${ }^{1,2}$ Today, they are frequently applied as model compounds to illustrate new achievements in multiple scientific areas, including biology, chemistry, medicine, physics, including dyesensitized solar cells (DSSCs) and beyond. ${ }^{3}$ Conclusively, research aims to synthesize complex porphyrin architectures with diverse substitution patterns that show tailored functional properties, including organocatalytic activity, ${ }^{4}$ singlet oxygen delivery, ${ }^{5}$ and innovative sensors. ${ }^{6}$ As such, short but efficient syntheses or new functionalization reactions are highly sought after. ${ }^{7}$ However, the choice of which synthetic route to use to synthesize any particular porphyrin depends upon the symmetry features of the product itself.

The synthesis of regioisomerically enriched or pure porphyrin type isomers usually depends on the preparation of special pyrrolic precursors or the design of particular condensation strategies. That is because conventional condensation reactions of, e.g., 3,4-disubstituted pyrroles would result in the formation of statistical mixtures of all possible type isomers. Moreover, due to the very similar physicochemical properties of a set of type isomers, it is not trivial to separate these on a preparative scale. Thus, for example, etioporphyrin I (1) and coproporphyrin I tetramethyl ester are accessible by the tetramerization of $\alpha$-functionalized pyrroles, ${ }^{8}$ and so-called opp-porphyrins, in which like pyrrole rings are regiochemically situated opposite to each other, were prepared in a similar fashion. ${ }^{9}$ On the other hand, dipyrromethenes have been utilized in the syntheses of 1 and coproporphyrin I (5) (Figure 1). ${ }^{10}$ 


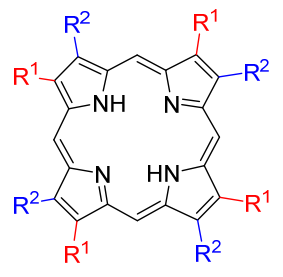

type I

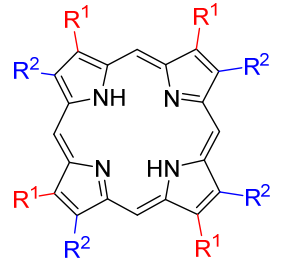

type III

e.g.,

1-4 $R^{1}=E t$

$R^{2}=M e$

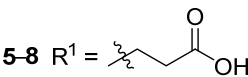

$R^{2}=\mathrm{Me}$

$9-12 R^{1}=3 /{ }^{O}{ }_{\mathrm{OH}}:$ uroporphyrin

$R^{2}$

$=\stackrel{\mathrm{O}}{\mathrm{O}}$
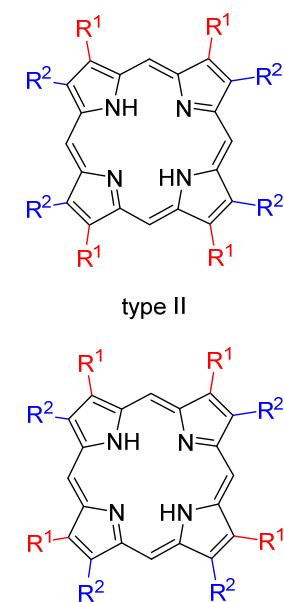

type IV

Figure 1: Examples of porphyrin type isomers: etioporphyrin I-IV (1-4) as well as biologically relevant copro- and uroporphyrin I-IV (5-8 and 9-12, respectively).

This methodology was later extended to the use of dipyrromethenes for the preparation of isomers other than type I. ${ }^{11}$ At the same time, where the separation of type isomers from statistical mixtures is attempted, time-consuming or small-scale purification methods are required, such as HPLC. Naturally, this is more challenging the more type isomers are present in a given sample. Type I and III isomers of penta-, hexa-, and heptacarboxyporphyrin as well as those of uro- (9 and 11), copro- (5 and 7), and isocoproporphyrin were separated via HPLC. ${ }^{12}$ The authors stated that this method would be suitable for the preparative isolation and for the detailed analysis of such isomers in clinical materials, e.g., urine and feces of patients. More recently, HPLC was also applied to separate coproporphyrin I and III (5 and 7) where tetrapyrroles were extracted from various types of yeast and bacteria and then analyzed by MS. ${ }^{13}$

Porphyrin type isomers ${ }^{14}$ are important for medicinal and synthetic studies: In one report, tetrapyrroles excreted by patients with different types of porphyria were 
analyzed..$^{15}$ Therein, the type isomer composition was disclosed with regards to, for example, type I and III uro- (9 and 11) and coproporphyrin (5 and 7) presence depending on the type of porphyria.

This overview shows that methods for the facile synthesis of regioisomerically pure porphyrin type isomers are scarce. Moreover, the synthetic approaches that were shown are usually not broadly applicable and as such, a relatively small library of such tetrapyrroles is at hand. This was taken as an occasion to elaborate a concept where simple Lindsey condensation reactions ${ }^{16}$ would lead to the preferential formation of type I porphyrins (Scheme 1).

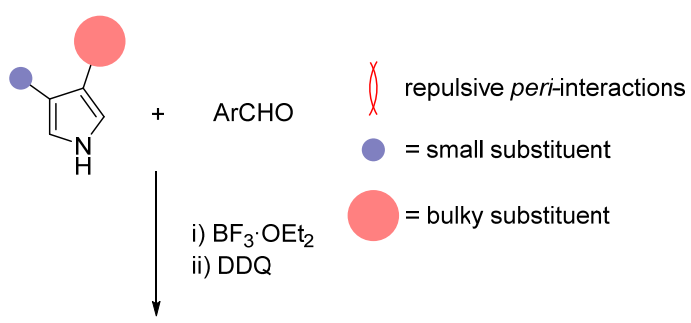

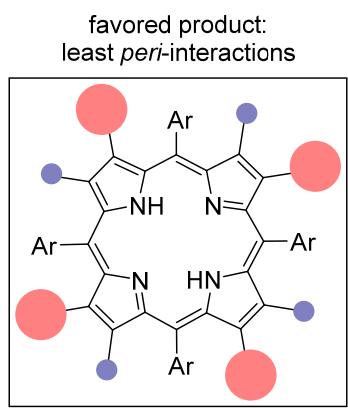

type I

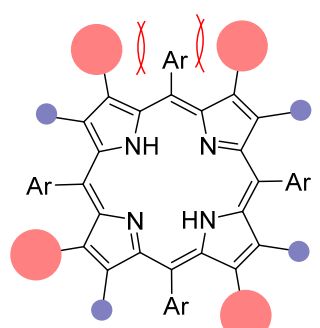

type III

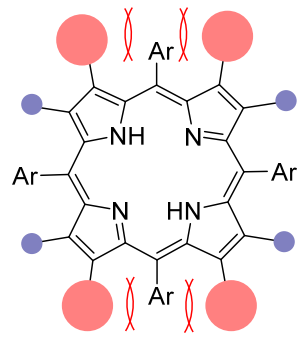

type II

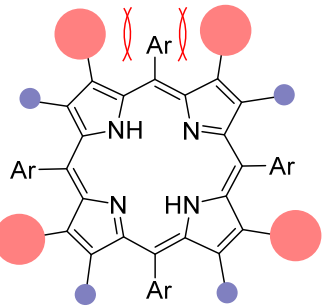

type IV

Scheme 1: Concept of the targeted synthesis of highly substituted type I porphyrins, rather than a statistical mixture, from unsymmetrical 3,4difunctionalized pyrroles and sterically demanding aldehydes.

In this proposal, the pyrrolic precursors are designed in a way that a significant difference in steric demand between the groups carried at the 3- vs the 4-position is 
generated (e.g., as in 14). When condensed with large aromatic aldehydes, type I porphyrins should be formed as the major products due to a minimization of the periinteractions and the reduction of the overall steric strain. peri-Interactions are conformational effects that occur when meso residues are flanked by $\beta$ substituents. ${ }^{17}$ This creates a steric clash, resulting in high energy steric strain and deformation of the molecule, which is particularly pronounced in dodecasubstituted porphyrins. ${ }^{18}$ For proof of principle, 3-ethyl-4-isopropylpyrrole (14) was prepared by the reduction of 3-acetyl-4-isopropylpyrrole (13) with lithium aluminium hydride in $84 \%$ yield. And indeed, the following reaction of compound 14 with benzaldehyde in the presence of the Lewis acidic $\mathrm{BF}_{3}$ catalyst yielded $15 \cdot 2 \mathrm{HCl}$ as the only detectable porphyrin species after the oxidation with 2,3-dichloro-5,6-dicyano-1,4-benzoquinone (DDQ, Scheme 2). Notably, 15 was obtained as a dihydrochloride salt, as indicated by the presence of only two $Q$ bands in the UV-vis absorption spectrum, likely due to the protonation by residual hydrochloric acid present in the solvent. This can be associated with the pronounced basicity of the neutral macrocycle 15 due to the high degree of nonplanarity and electron-rich character. ${ }^{4 c}$ The protonation could not be prevented even when the solvent was predried, neutralized over $\mathrm{K}_{2} \mathrm{CO}_{3}$, and filtered through silica before use. And while the compound could initially be neutralized through the addition of DCM:TFA (100:1, v/v), redissolving in DCM or chloroform resulted in anew protonation. As such, for the purpose of this study, further neutralization attempts of the complex (e.g., drying over $\mathrm{CaH}_{2}$, followed by distillation) were ultimately not attempted.

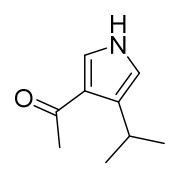

13

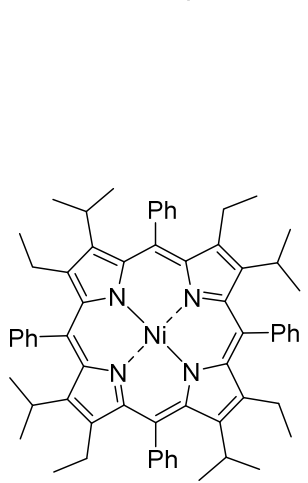

16

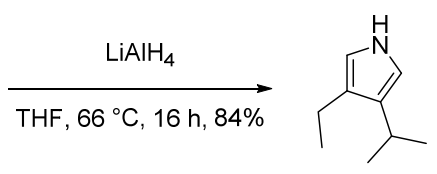

14

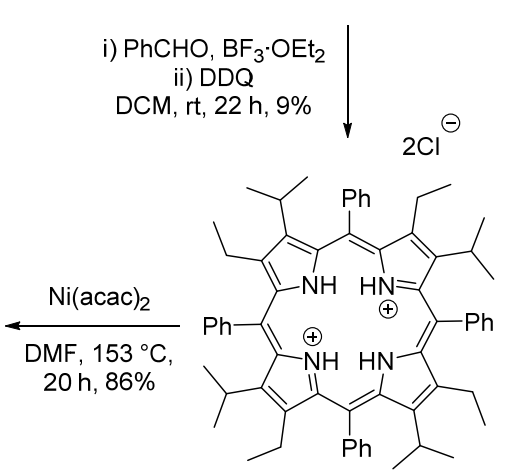

$15 \cdot 2 \mathrm{HCl}$ 
Scheme 2. Synthesis of type I porphyrin isomers $15 \cdot 2 \mathrm{HCl}$ and 16 through condensation and metalation.

The formation of the type I isomer $15 \cdot 2 \mathrm{HCl}$ was confirmed with certainty by single crystal X-ray analysis. Interestingly, the alternating ethyl-isopropyl type I substituent pattern resulted in an overall molecular shape resembling a macroscopic propeller or a Dutch windmill where the isopropyl groups are analogous to molecular-scale blades attached at a precise $90^{\circ}$ pitch angle. To investigate the features of the corresponding metalloporphyrin 16 , and for comparison with $15 \cdot 2 \mathrm{HCl}, \mathrm{Ni}(\mathrm{II})$ insertion was performed, which occurred in a high yield of $86 \%$. The crystal structures of both $15 \cdot 2 \mathrm{HCl}$ and the $\mathrm{Ni}(\mathrm{II})$ complex 16 revealed a severe saddle distortion of each macrocycle (Figure 2).
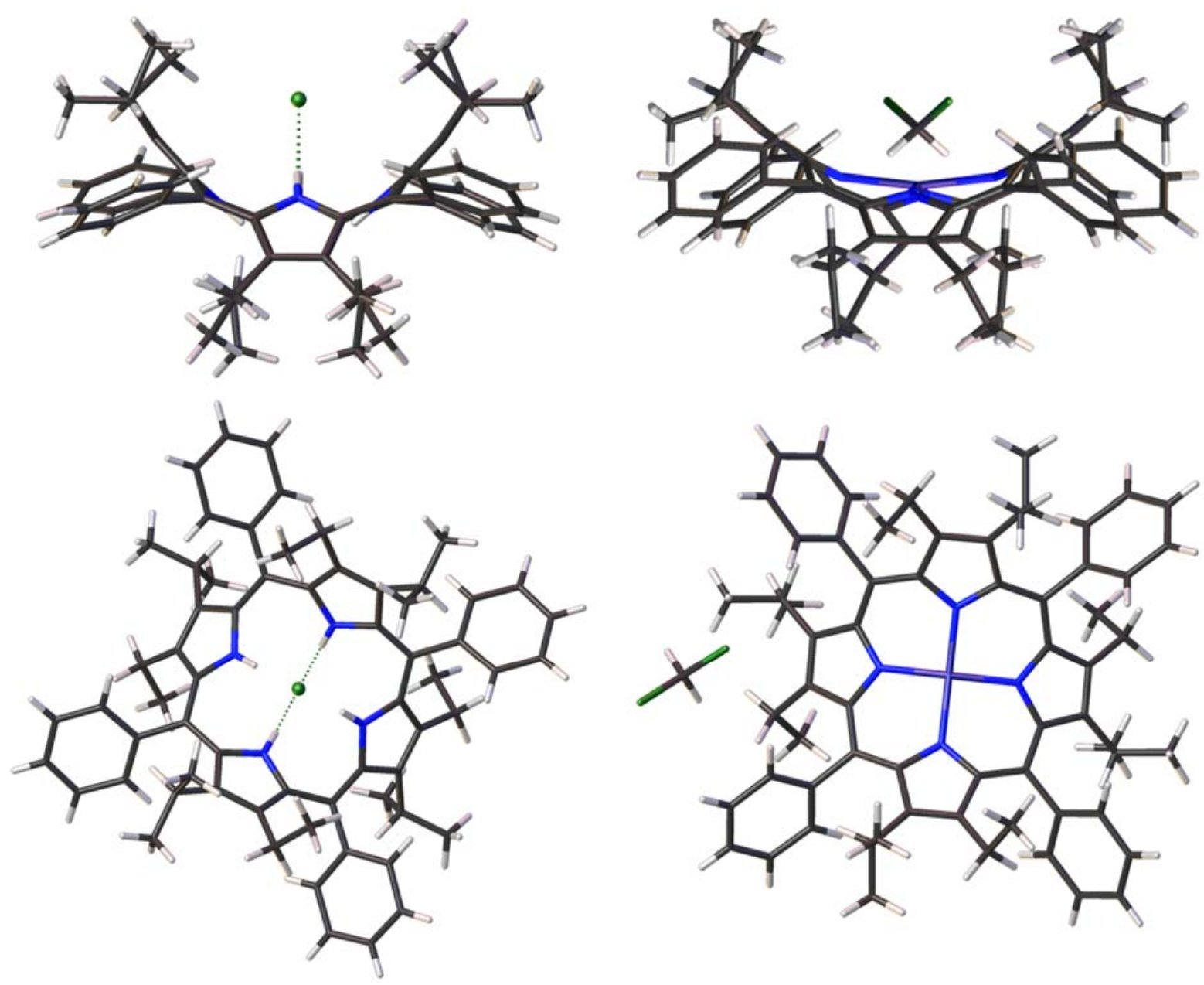

Figure 2: Side and top views (stick models) of $15 \cdot 2 \mathrm{HCl}$ (left) and $16 \cdot \mathrm{DCM}$ (right). ${ }^{19 a}$ One of the chloride ions has been omitted for clarity. 
In addition, the crystal lattice of $\mathbf{1 6}$ had a tunnel-like structure where DCM was incorporated (Figure 3). Moreover, the isopropyl substituents extended well beyond the porphyrin plane, with the result that the DCM guest molecules were fully engulfed in hydrophobic binding pockets. The formation of this nonplanar metalloporphyrin solvate complex is somewhat reminiscent of $\{2,3,7,8,12,13,17,18$-octaethyl5,10,15,20-tetraphenylporphyrinato\}copper(II) dichloromethane solvate $(\mathrm{Cu}(\mathrm{II}) \mathrm{OETPP} \cdot 2 \mathrm{DCM})$ and points at possible receptor applications due to the availability of solvent-accessible voids ${ }^{4 a, 20}$ or at enzyme-like catalytic properties due to the presence of hydrophobic cavities.

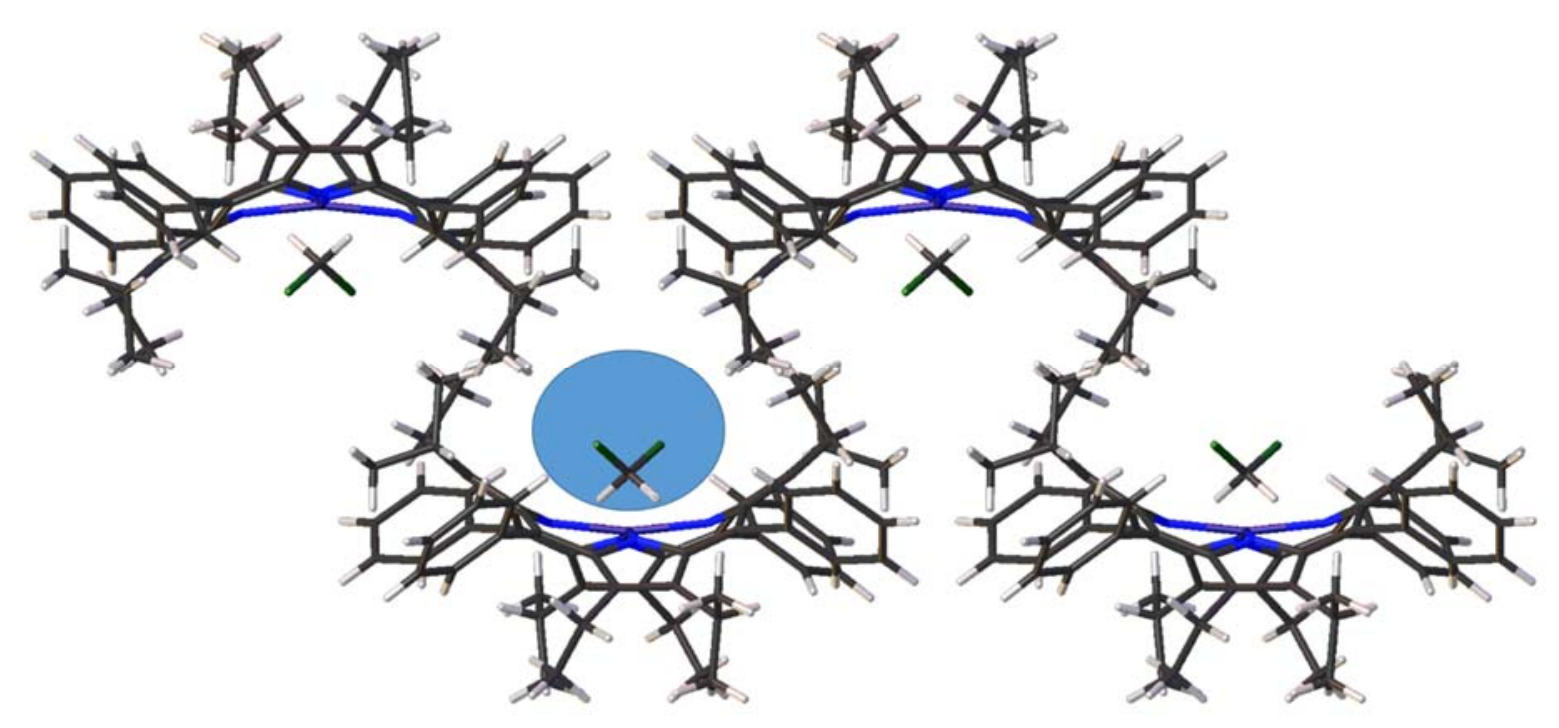

Figure 3: Excerpt of the crystal structure lattice diagram (stick model) of 16.DCM. ${ }^{19 a}$ The blue circle marks a hydrophobic binding pocket.

The selective formation of $15 \cdot 2 \mathrm{HCl}$ confirmed the initial hypothesis that the rational choice of the pyrrole and aldehyde components would open a new avenue to regioisomerically pure type I porphyrins via simple condensation pathways. In order to expand the product library, 14 was also reacted with 4-methoxybenzaldehyde with a similar outcome (Scheme 3). 


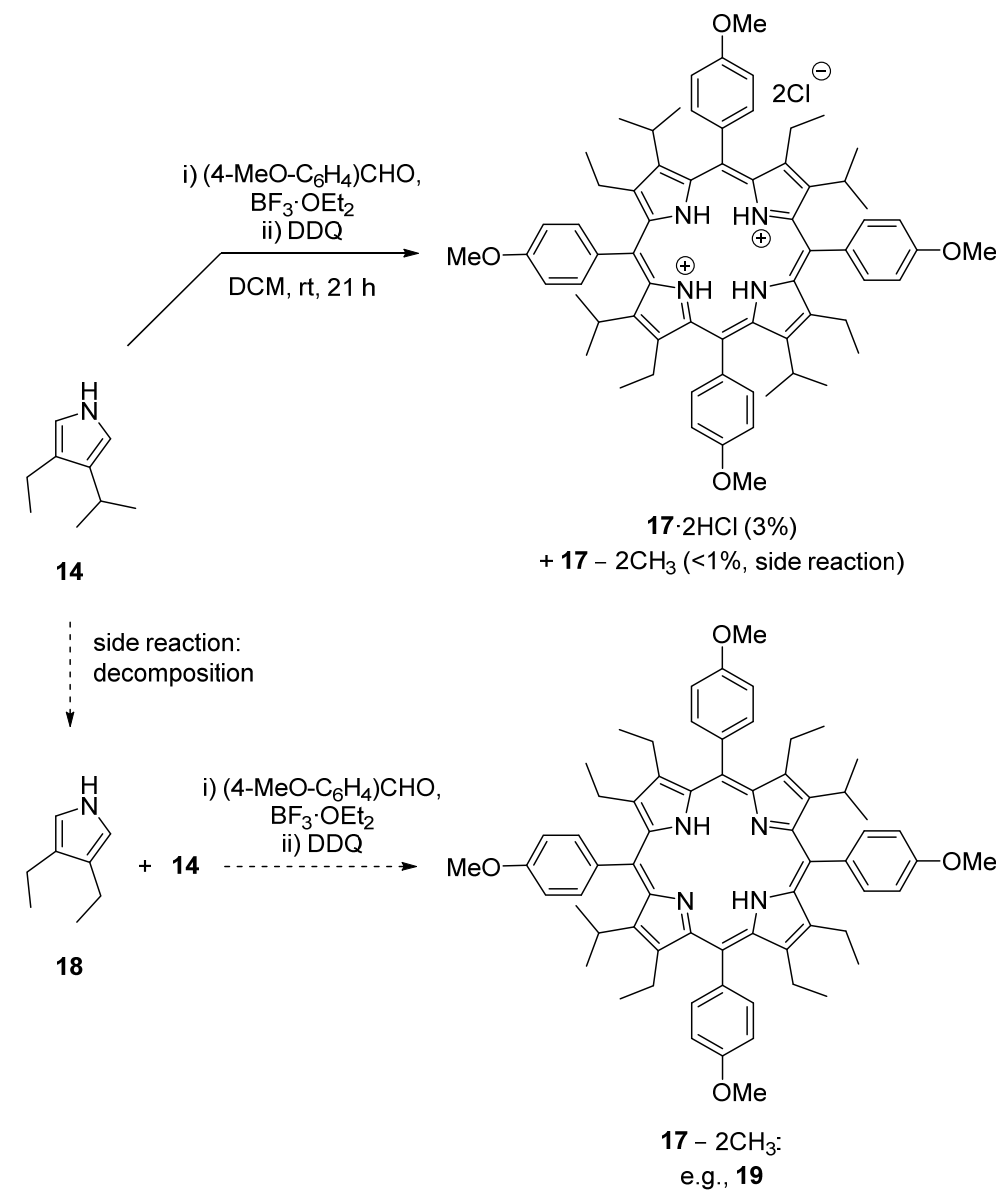

Scheme 3 . Synthesis of the type I porphyrin $17 \cdot 2 \mathrm{HCl}$ through a condensation reaction.

While the only porphyrin type isomer that could be observed and isolated was $17 \cdot 2 \mathrm{HCl}$, the presence of another species after the condensation reaction was noted. This tetrapyrrole could be readily separated from $17 \cdot 2 \mathrm{HCl}$, but no structure was assigned with certainty. However, HRMS analysis indicated that this porphyrin was devoid of two $\mathrm{CH}_{3}$ fragments $\left(17-2 \mathrm{CH}_{3}\right)$ when compared to 17 . One explanation is that a fraction of $\mathbf{1 4}$ underwent a type of dealkylation prior to the condensation to form 3,4-diethylpyrrole (18), which could then have reacted with unaltered 14 and 4methoxybenzaldehyde to form a tetrapyrrole like 19 or corresponding regioisomers (Scheme 3). But at this stage, the actual molecular structure of, and the mechanism for the formation of $17-2 \mathrm{CH}_{3}$, and whether this is a mixture of isomers is speculation. In any case, this side product could be separated from $17 \cdot 2 \mathrm{HCl}$ through conventional column chromatography, and unambiguous assignment of the structure is currently under investigation. 
In the following, it was attempted to extend this method to different types of pyrroles and to investigate some of the limitations. For this, 3-methyl-4-phenylpyrrole (23) was selected as a promising target in order to test whether it would be possible to introduce aromatic functions into the $\beta$-positions of type I porphyrins. In practical terms, $\mathbf{2 3}$ was synthesized from 20 and $p$-toluenesulfonylmethyl isocyanide (21) in a sequence of a Van Leusen reaction ${ }^{21}$ and a reduction of the methyl ester function in $\mathbf{2 2}$ (Scheme 4). Unfortunately, the condensation of $\mathbf{2 3}$ with benzaldehyde resulted in the formation of an inseparable statistical mixture of all four porphyrin isomers. Apparently, the difference in steric bulk between the methyl and phenyl group in $\mathbf{2 3}$ was not distinct enough for selective type I porphyrin formation. While the 4-phenyl substituent in $\mathbf{2 3}$ may be considered as a large functional group, the flat geometry of this group may account for an insufficient distinction from the 3-methyl unit in terms of bulkiness and, consequently, the lack of regioselectivity. This was reflected by a high number of methyl signals in the ${ }^{1} \mathrm{H}$ NMR spectra of the free base products and the corresponding $\mathrm{Ni}(\mathrm{II})$ complexes. The $\mathrm{Ni}(\mathrm{II})$ complexes were synthesized to investigate whether a separation by chromatography could be accomplished. But unfortunately, the TLC analysis indicated a very similar polarity of the products. However, this example did not eliminate the option that in the future, 3,4-disubstituted pyrroles with more sterically demanding aromatic substituents may eventually lead to type I porphyrin formations.

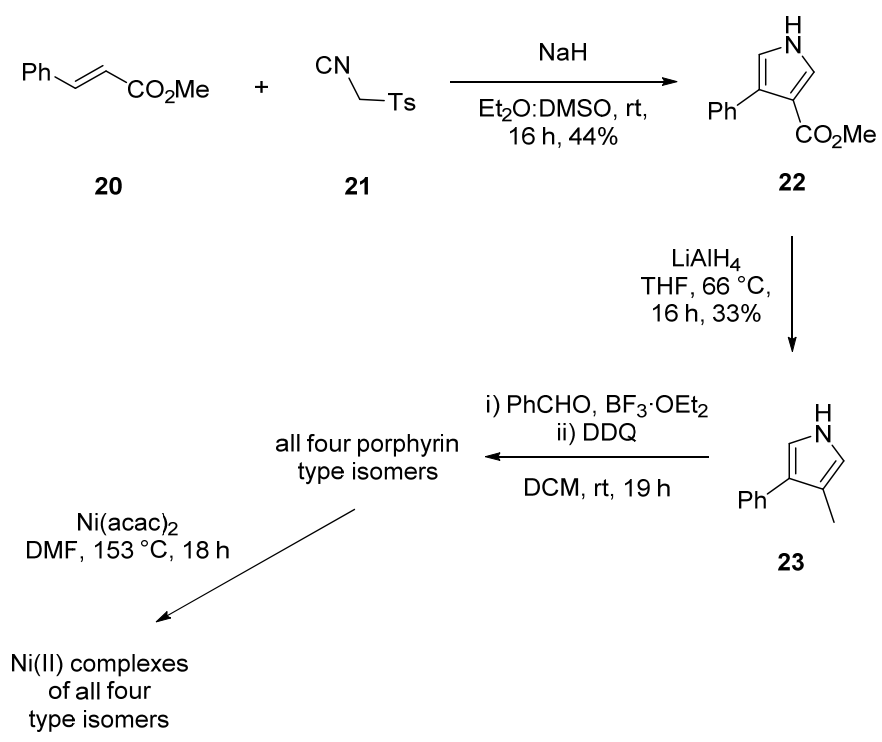

Scheme 4: Synthesis of 3-methyl-4-phenylpyrrole (23), acid-catalyzed condensation with benzaldehyde, and metalation. 
Upon recrystallization of the pyrroles 14 and 23, samples that were suitable for single crystal X-ray analysis could be obtained. The structural analysis revealed the formation of intermolecular $\mathrm{H}$-bonds in both species between the polarized carbonyl functions and $\mathrm{N}-\mathrm{H}$ groups (Figure 4). This was an interesting observation since $\mathrm{H}-$ bonding of the nitrogenous hydrogen atoms in pyrroles is an important feature for the application as catalysts ${ }^{4,22}$ and innovative sensors. ${ }^{23}$
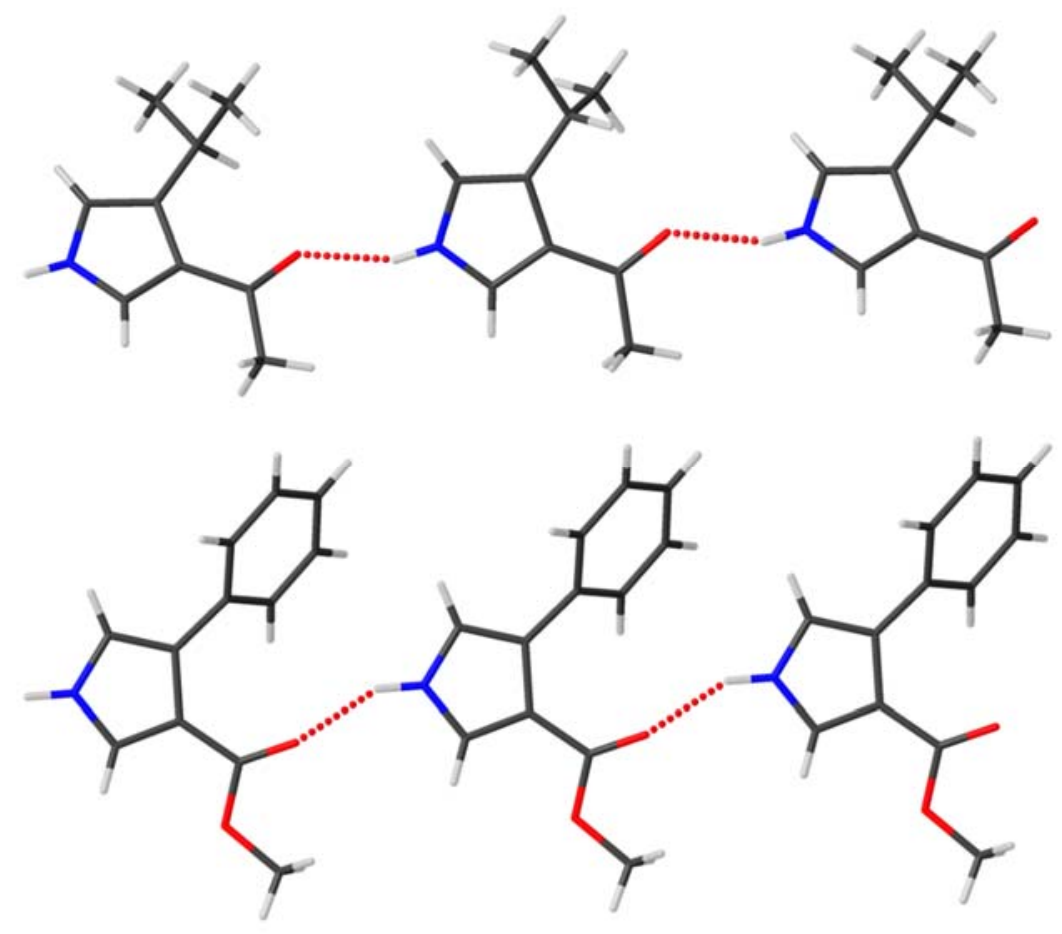

Figure 4: Excerpts of the crystal structure lattice diagrams (stick models) of 13 (top) and 22 (bottom), both revealing the formation of intermolecular H-bonds. ${ }^{19 a}$

To conclude, a method for the selective preparation of type I porphyrins in straightforward condensation reactions was developed, and the utility of the method could be proven in a promising case study. Therein, dodecasubstituted type I porphyrins formed as the only regioisomers, and it is likely that the presence of a higher number of repulsive peri-interactions in the type II, III, and IV tetrapyrroles is responsible for the high degree of regioselectivity. Notably, this innovative method does not depend on tedious precursor syntheses, cumbersome purification steps (i.e., HPLC), or impractical limitations on the reaction scale that are usually associated with this type of chemistry. While this strategy was initially investigated for 3,4dialkylpyrroles, an expansion to more diverse systems is currently under investigation. 
Moreover, the crystal structural analyses of $15 \cdot 2 \mathrm{HCl}$ and 16 confirmed the type I substitution pattern, likewise revealing a high degree of saddle distortion in both. Interestingly, the $\mathrm{Ni}(\mathrm{II})$ complex 16 formed a tunnel-like structure in the solid state and acted as a receptor for DCM, which could be exploited for the sensing of neutral molecules in the future. Additionally, the crystal structures of the unsymmetrically 3,4difunctionalized pyrroles 14 and 23, which formed intermolecular $\mathrm{H}$-bonds due to the presence of carbonyl and $\mathrm{N}-\mathrm{H}$ groups, were solved, pointing at a potential as sensors and organocatalysts. ${ }^{24}$

\section{EXPERIMENTAL SECTION}

Analytical Techniques. Analytical TLC was performed using sheets precoated with silica gel to a depth of $0.2 \mathrm{~mm}$ or aluminum oxide plates, both impregnated with fluorescence indicator $F_{254}$. The visualization was accomplished with a UV lamp. Flash column chromatography was carried out using aluminum oxide (neutral, activated with $6 \% \mathrm{H}_{2} \mathrm{O}$, Brockman Grade III). Mass spectrometry analysis was performed with a QTof Premier Waters MALDI quadrupole time-of-flight (Q-TOF) mass spectrometer equipped with a matrix-assisted laser desorption ionization (MALDI) source and DCTB (trans-2-[3-(4-tert-butylphenyl)-2-methyl-2-propenylidene]malononitrile) as the matrix. APCl experiments were performed on a Bruker microTOF-Q III spectrometer interfaced to a Dionex UltiMate 3000 LC. UV-vis absorption measurements were performed in DCM as the solvent using a Shimadzu MultiSpec-1501. Melting points are uncorrected and were measured with a Stuart SMP-50 melting point apparatus. ${ }^{1} \mathrm{H}$ and ${ }^{13} \mathrm{C}\left\{{ }^{1} \mathrm{H}\right\}$ NMR spectra were recorded at $400.13 \mathrm{MHz}$ and $100.61 \mathrm{MHz}$, respectively, using Bruker DPX400, Bruker AV 600, and Bruker AV 400 devices, respectively. All NMR experiments were performed at $25^{\circ} \mathrm{C}$. Resonances $\delta$ are given in ppm units and referenced to the deuterium peak in the $\mathrm{NMR}$ solvent $\mathrm{CDCl}_{3}(\delta \mathrm{H}=$ $7.26 \mathrm{ppm}, \delta \mathrm{c}=77.2 \mathrm{ppm}$ ). Signal multiplicities are abbreviated as follows: singlet $=\mathrm{s}$, doublet $=\mathrm{d}$, quartet $=\mathrm{q}$, septet $=$ sept, multiplet $=\mathrm{m}$. IR spectra were recorded on $\mathrm{a}$ PerkinElmer Spectrum 100 FTIR spectrometer utilizing the ATR sampling technique.

General Information. To protect air and moisture sensitive compounds, the corresponding reactions were carried out under "Schlenk" conditions using argon as 
an inert gas. Air and residual moisture were removed from the instruments by a hot air gun under high vacuum, and the flasks were purged with argon subsequently. This cycle was repeated up to three times as necessary.

In the NMR spectra of the new highly substituted type I porphyrins, the signals corresponding to the $\beta$-ethyl and $\beta$-isopropyl groups are broad. This is in accordance with conformational studies by Medforth et al. on decaalkylporphyrins. ${ }^{25}$ Presumably, the highly substituted products existed as a mixture of atropisomers in solution. The missing signals corresponding to the inner protons, as observed in most ${ }^{1} \mathrm{H}$ NMR spectra, have been reported previously, too. ${ }^{26}$

Materials. Most commercially available reagents were used as received unless otherwise noted. For example, THF and DCM for air and moisture sensitive reactions were obtained by passing the degassed solvents through an activated aluminium oxide column. Alternatively, DCM for porphyrin syntheses was obtained via drying over

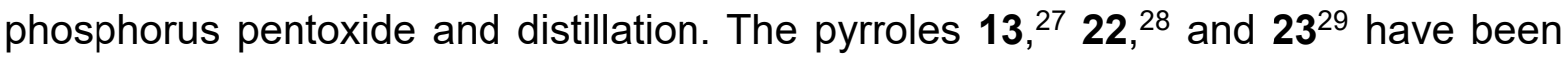
prepared following the literature.

3-Ethyl-4-isopropylpyrrole 14: 3-Acetyl-4-isopropylpyrrole $13(4 \mathrm{~g}, 26.5 \mathrm{mmol}, 1$ equiv) in $70 \mathrm{~mL}$ THF was added dropwise to a suspension of $\mathrm{LiAlH}_{4}(3.14 \mathrm{~g}, 82.7$ mmol, 3.1 equiv) in $20 \mathrm{~mL}$ THF at $0{ }^{\circ} \mathrm{C}$. After that, the reaction mixture was left to stir for $1 \mathrm{~h}$ at it and heated to $66{ }^{\circ} \mathrm{C}$ for $17 \mathrm{~h}$ by an oil bath. Upon the careful hydrolysis with $\approx 150 \mathrm{~mL}$ of a $2 \mathrm{M}$ sodium hydroxide solution at $0{ }^{\circ} \mathrm{C}, \mathrm{Et}_{2} \mathrm{O}$ was added, and the layers were separated. The aqueous phase was extracted with $\mathrm{Et}_{2} \mathrm{O}$, and the combined organic layers were washed with water, dried with $\mathrm{MgSO}_{4}$, filtered, and the solvent was removed in vacuo. The title compound was obtained as yellow oil ( $3.05 \mathrm{~g}$, $22.26 \mathrm{mmol}, 84 \%) \cdot R_{\mathrm{f}} 0.55$ ( $\mathrm{SiO}_{2}$, hexane). ${ }^{1} \mathrm{H} \mathrm{NMR}\left(\mathrm{CDCl}_{3}, 400.13 \mathrm{MHz}\right): \delta 1.36-1.42$ (m, 9H), 2.68 (q, $J=7.5 \mathrm{~Hz}, 2 \mathrm{H}$ ), 3.02 (sept, $J=6.8 \mathrm{~Hz}, 1 \mathrm{H}$ ), 6.65 (d, $J=2.7 \mathrm{~Hz}, 2 \mathrm{H}$ ), $7.91(\mathrm{~s}, 1 \mathrm{H}) .{ }^{13} \mathrm{C}\left\{{ }^{1} \mathrm{H}\right\} \mathrm{NMR}\left(\mathrm{CDCl}_{3}, 100.61 \mathrm{MHz}\right): \delta 14.6,18.5,24.0,25.2,113.3,114.6$, 124.0, 129.8. HRMS-APCl $(\mathrm{m} / \mathrm{z})$ : $[\mathrm{M}+\mathrm{H}]^{+}$calcd for $\mathrm{C}_{9} \mathrm{H}_{16} \mathrm{~N}, 138.1277$; found, 138.1281. MS-APCI $\mathrm{m} / \mathrm{z}$ (\% relative intensity, ion): $96.07\left(100, \mathrm{M}-\mathrm{C}_{3} \mathrm{H}_{7}+2 \mathrm{H}\right)$. IR (ATR) $\tilde{V}_{\text {max: }}$ 2959, 2931, 2870, 1670, 1640, 1462, 1379, 1076, 896, $776 \mathrm{~cm}^{-1}$.

\section{2,7,12,17-Tetraethyl-3,8,13,18-tetraisopropyl-5,10,15,20-tetraphenyl-22H,24H-}


porphyrindiium dihydrochloride $15 \cdot 2 \mathrm{HCl}$ : 3-Ethyl-4-isopropylpyrrole $(14,1 \mathrm{~g}, 7.29$ mmol, 1 equiv) and benzaldehyde ( $0.77 \mathrm{~g}, 7.29 \mathrm{mmol}, 1$ equiv) were dissolved in dry DCM $(1 \mathrm{~L})$ and boron trifluoride diethyl etherate $(90 \mu \mathrm{L}, 0.73 \mathrm{mmol}, 10 \mathrm{~mol} \%$ ) was added. This was reacted for $22 \mathrm{~h}$ at $\mathrm{rt}$, followed by the addition of DDQ $(7.28 \mathrm{~g}, 32.1$ mmol, 4.4 equiv). The solution became purple and was left to stir for another hour. The solvent was removed at reduced pressure, the residue was dissolved in DCM and filtered through a plug of $\mathrm{Al}_{2} \mathrm{O}_{3}$, Brockman grade III, using $\mathrm{DCM}$, mixtures of $D C M$ and ethyl acetate, and eventually mixtures of ethyl acetate and methanol to partly separate the relevant green fractions. These were evaporated to dryness and chromatographed on $\mathrm{Al}_{2} \mathrm{O}_{3}$, Brockman grade III, using DCM:ethyl acetate, 2:1, v/v. A major green band was isolated, which contained the title compound. After drying in vacuo, $15 \cdot 2 \mathrm{HCl}$ was obtained as green solid (172 mg, $0.66 \mathrm{mmol}, 9 \%)$ mp > $300{ }^{\circ} \mathrm{C} . R_{\mathrm{f}} 0.34\left(\mathrm{Al}_{2} \mathrm{O}_{3}\right.$, DCM:ethyl acetate, 10:1, v/v). ${ }^{1} \mathrm{H}$ NMR $\left(\mathrm{CDCl}_{3}, 400.13 \mathrm{MHz}\right): \delta-0.34(\mathrm{~s}, 4 \mathrm{H}),-0.17-$ $0.58(\mathrm{~m}, 24 \mathrm{H}), 1.38-1.55(\mathrm{~m}, 12 \mathrm{H}), 2.12-2.33(\mathrm{~m}, 4 \mathrm{H}), 2.41-2.74(\mathrm{~m}, 8 \mathrm{H}), 7.73-7.98$ $(\mathrm{m}, 12 \mathrm{H}), 8.39-8.72(\mathrm{~m}, 8 \mathrm{H}) .{ }^{13} \mathrm{C}\left\{{ }^{1} \mathrm{H}\right\} \mathrm{NMR}\left(\mathrm{CDCl}_{3}, 100.61 \mathrm{MHz}\right): \delta 14.7,15.9,16.4$, $16.5,16.6,16.7$ ( × 3), 19.6 (× 2), 19.8, 23.0, 23.1, $23.2(\times 2), 23.3(\times 2), 27.4,27.5$, $32.2,118.1,118.2,118.5,118.7$ (× 2), 118.8, 119.1, 128.7, 128.8, $128.9(\times 2), 129.0(\times$ 2), $129.1,130.0(\times 2), 130.1,130.7,134.3,137.3,137.4(\times 2), 137.6,137.7,137.8$ (× 2), $137.9(\times 2), 138.4,138.7,138.9,139.1(\times 2), 139.2,139.3,139.5,139.7,139.9$, $140.2,140.8,140.9,141.1,141.2$ (× 2), 141.5, 144.9, $145.0(\times 2), 145.1,145.2,145.4$, 145.5, 145.6, 145.7 (× 2), 145.8, 145.9, 146.0, 146.2. UV-vis (DCM) $\lambda_{\max }(\log \varepsilon): 484$ (5.57), 646 (4.09), $703 \mathrm{~nm}$ (4.69). HRMS-MALDI (m/z): [M - 2HCl + H] calcd for $\mathrm{C}_{64} \mathrm{H}_{71} \mathrm{~N}_{4}, 895.5673$; found, 895.5670.

\section{2,7,12,17-Tetraethyl-3,8,13,18-tetraisopropyl-5,10,15,20-}

tetraphenylporphyrinato\}nickel(II) 16: Porphyrin 15.2HCl $(60.3 \mathrm{mg}, 62 \mu \mathrm{mol}, 1$ equiv) and $\mathrm{Ni}($ acac)2 (159 mg, $0.62 \mathrm{mmol}, 10$ equiv) were dissolved in $0.6 \mathrm{~mL} \mathrm{DMF}$, and this was heated to $153^{\circ} \mathrm{C}$ for $20 \mathrm{~h}$ by a heating mantle during which the reaction mixture changed color from green to purple. After cooling to rt, water and DCM were added, and the layers were separated. The aqueous phase was extracted with DCM and the combined organic layers were washed with water, dried with $\mathrm{MgSO}_{4}$, filtered, and the solvent was evaporated in vacuo. The purple crude product was purified by column chromatography $\left(\mathrm{Al}_{2} \mathrm{O}_{3}\right.$, Brockman grade III, using DCM:petroleum ether, 
$1: 10, v / v)$. The first fraction, a purple band, was isolated and upon evaporation of the solvent, the title compound was obtained as purple solid ( $51 \mathrm{mg}, 53.3 \mu \mathrm{mol}, 86 \%$ ). mp $>300{ }^{\circ} \mathrm{C} . R_{\mathrm{f}} 0.61\left(\mathrm{SiO}_{2}\right.$, hexane:DCM, 5:1, v/v). ${ }^{1} \mathrm{H}$ NMR $\left(\mathrm{CDCl}_{3}, 400.13 \mathrm{MHz}\right): \delta 0.33-$ $0.49(\mathrm{~m}, 12 \mathrm{H}), 0.54-0.77(\mathrm{~m}, 12 \mathrm{H}), 1.26-1.45(\mathrm{~m}, 12 \mathrm{H}), 1.79-2.09(\mathrm{~m}, 4 \mathrm{H}), 2.52-2.83$ $(\mathrm{m}, 8 \mathrm{H}), 7.53-7.70(\mathrm{~m}, 12 \mathrm{H}), 7.94-8.21(\mathrm{~m}, 8 \mathrm{H}) .{ }^{13} \mathrm{C}\left\{{ }^{1} \mathrm{H}\right\} \mathrm{NMR}\left(\mathrm{CDCl}_{3}, 100.61 \mathrm{MHz}\right)$ : $\delta 17.6,20.4,23.2,26.7,26.8,26.9,127.0,127.3,127.7,127.8,127.9,128.1,134.2$, 134.7, 135.3, 140.7, 146.3, 146.5, 148.7, 148.9. UV-vis (DCM) $\lambda_{\max }(\log \varepsilon): 444$ (5.33), 593 (4.15), $599 \mathrm{~nm}$ (4.01). HRMS-MALDI ( $\mathrm{m} / \mathrm{z})$ : [M] ${ }^{+}$calcd for $\mathrm{C}_{64} \mathrm{H}_{68} \mathrm{~N} 4 \mathrm{Ni}, 950.4797$; found, 950.4785 .

\section{2,7,12,17-Tetraethyl-3,8,13,18-tetraisopropyl-5,10,15,20-tetrakis(4- methoxyphenyl)-22H,24H-porphyrindiium dihydrochloride $17 \cdot 2 \mathrm{HCl}$ :}

Similar to the synthesis of $15 \cdot 2 \mathrm{HCl}$, 3-ethyl-4-isopropylpyrrole $(14,0.5 \mathrm{~g}, 3.6 \mathrm{mmol}$, 1.1 equiv) and 4-methoxybenzaldehyde ( $0.4 \mathrm{~mL}, 3.3 \mathrm{mmol}$, 1 equiv) were dissolved in $500 \mathrm{~mL}$ of dry $\mathrm{DCM}$ and $\mathrm{BF}_{3} \cdot \mathrm{OEt}_{2}(43 \mu \mathrm{L}, 0.33 \mathrm{mmol}, 10 \mathrm{~mol} \%)$ was added. This was reacted at $\mathrm{rt}$ for $21 \mathrm{~h}$ during which the reaction mixture turned red, followed by DDQ addition ( $3.3 \mathrm{~g}, 14.52 \mathrm{mmol}, 4.4$ equiv). After stirring for another $2 \mathrm{~h}$, the solvent was removed in vacuo and the residue dissolved in $\mathrm{DCM}$ and filtered through $\mathrm{Al}_{2} \mathrm{O}_{3}$, Brockman grade IIII, using DCM and DCM:ethyl acetate mixtures up to pure ethyl acetate to remove DDQ derivatives and other nonporphyrin material. Then, DCM:methanol, 1:1, v/v was applied to isolate a green/brown fraction. The relevant fractions, which had brown or green/brown colors, were combined upon TLC analysis, and the solvent was evaporated. The crude product was then subjected to column chromatography. Column chromatography $\left(\mathrm{Al}_{2} \mathrm{O}_{3}\right.$, Brockman grade IIII) was performed using DCM to remove brown impurities, then DCM:ethyl acetate, 10:1, v/v to isolate a light green fraction of $17 \cdot 2 \mathrm{HCl}$, giving a green solid $(27 \mathrm{mg}, 0.1 \mathrm{mmol}, 3 \%)$ upon evaporation of the solvent. Second, a porphyrin (e.g., 19, see Scheme 3) that was devoid of two $\mathrm{CH}_{3}$ fragments when compared to 17 , as indicated by HRMS analysis, was eluted as a dark green band, yielding a green solid ( $5 \mathrm{mg},<1 \%)$ after evaporation of the solvent. $17 \cdot 2 \mathrm{HCl}: \mathrm{mp} 286-290^{\circ} \mathrm{C}$ dec. $R \mathrm{f} 0.67\left(\mathrm{Al}_{2} \mathrm{O}_{3}, \mathrm{DCM}\right.$ :ethyl acetate, $10: 1, \mathrm{v} / \mathrm{v}) .{ }^{1} \mathrm{H}$ NMR $\left(\mathrm{CDCl}_{3}, 400.13 \mathrm{MHz}\right): \delta 0.02-0.24(\mathrm{~m}, 12 \mathrm{H}), 0.25-0.38$ $(\mathrm{m}, 12 \mathrm{H}), 1.44-1.54(\mathrm{~m}, 12 \mathrm{H}), 2.21-2.39(\mathrm{~m}, 4 \mathrm{H}), 2.44-2.71(\mathrm{~m}, 8 \mathrm{H}), 4.09(\mathrm{~s}, 3 \mathrm{H})$, $4.11(\mathrm{~s}, 6 \mathrm{H}), 4.12(\mathrm{~s}, 3 \mathrm{H}), 7.35-7.44(\mathrm{~m}, 8 \mathrm{H}) 8.31-8.55(\mathrm{~m}, 8 \mathrm{H}) .{ }^{13} \mathrm{C}\left\{{ }^{1} \mathrm{H}\right\} \mathrm{NMR}\left(\mathrm{CDCl}_{3}\right.$, 
100.61 MHz): $\delta 15.7,15.8,15.9(\times 2), 16.0,19.1,26.6,26.7,113.7,114.1(\times 2), 116.6$, $116.8,117.2$, 117.4, 117.7, 118.0, 130.4, 131.5, 131.8, 132.7, 133.0, 137.5, 137.8, $137.9,138.0,138.1,138.4,138.5$ (× 2), 138.6, 139.6, 139.7, 140.0, 140.5, 144.8, $144.9,145.0,145.3,145.4$, 145.6, 145.7, 145.8, 146.0, 146.3, 146.5, 161.0, 161.1. UV-vis (DCM) $\lambda_{\max }(\log \varepsilon): 486$ (5.63), $722 \mathrm{~nm}$ (4.87). HRMS-MALDI (m/z): [M - H $2 \mathrm{Cl}^{+}$calcd for $\mathrm{C}_{68} \mathrm{H}_{79} \mathrm{~N}_{4} \mathrm{O}_{4}, 1015.6101$; found, 1015.6074. $17-2 \mathrm{CH}_{3}$ (e.g., 19): HRMS-MALDI (m/z): [M - 2HCl + $\mathrm{H}]^{+}$calcd for $\mathrm{C}_{62} \mathrm{H}_{67} \mathrm{~N}_{4}, 867.5360$; found, 867.5371.

\section{SUPPORTING INFORMATION}

${ }^{1} \mathrm{H}$ and ${ }^{13} \mathrm{C}$ NMR spectra of the newly synthesized compounds, single crystal X-ray structures, and ${ }^{1} \mathrm{H}$ NMR spectra of statistical porphyrin type isomer mixtures. This material is available free of charge via the Internet at http://pubs.acs.org. CCDC 1993404-1993407 contain the supplementary crystallographic data for this note. These data can be obtained free of charge from The Cambridge Crystallographic Data Centre (CCDC) via www.ccdc.cam.ac.uk/data_request/cif.

\section{ACKNOWLEDGMENTS}

This work was supported by grants from Science Foundation Ireland (SFI IVP 13/IA/1894) and through funding from the European Union's Horizon 2020 research and innovation program under the FET Open grant agreement no. 828779.

\section{REFERENCES}

(1) Huber, R. "A structural basis of light energy and electron transfer in biology", Eur. J. Biochem. 1990, 187, 283-305.

(2) (a) Senge, M. O.; MacGowan, S. A.; O'Brien, J. M. "Conformational control of cofactors in nature - the influence of protein-induced macrocycle distortion on the biological function of tetrapyrroles", Chem. Commun. 2015, 51, 17031-17063; (b) Senge, M. O. "N-H Hydrogen Bonding in Porphyrins - from Conformational Design to Supramolecular Chemistry", ECS Trans. 2015, 66, 1-10. 
(3) (a) Zeng, K.; Tong, Z.; Ma, L.; Zhu, W.-H.; Wu, W.; Xie, Y. "Molecular engineering strategies for fabricating efficient porphyrin-based dye-sensitized solar cells", Energy Environ. Sci. 2020, Advanced Article, doi: 10.1039/C9EE04200H; (b) Kurumisawa, Y.; Higashino, T.; Nimura, S.; Tsuji, Y.; liyama, H.; Imahori, H. "Renaissance of Fused Porphyrins: Substituted Methylene-Bridged Thiophene-Fused Strategy for HighPerformance Dye-Sensitized Solar Cells", J. Am. Chem. Soc. 2019, 141, 9910-9919; (c) Kielmann, M.; Prior, C.; Senge, M. O. "Porphyrins in troubled times: a spotlight on porphyrins and their metal complexes for explosives testing and CBRN defense", New J. Chem. 2018, 42, 7529-7550; (d) Ding, Y.; Zhu, W.-H.; Xie, Y. "Development of Ion Chemosensors Based on Porphyrin Analogues", Chem. Rev. 2017, 117, 2203-2256; (e) Zou, Q.; Abbas, M.; Zhao, L.; Li, S.; Shen, G.; Yan, X. "Biological Photothermal Nanodots Based on Self-Assembly of Peptide-Porphyrin Conjugates for Antitumor Therapy", J. Am. Chem. Soc. 2017, 139, 1921-1927; ( $f$ ) Rawson, J.; Stuart, A. C.; You, W.; Therien, M. J. "Tailoring Porphyrin-Based Electron Accepting Materials for Organic Photovoltaics", J. Am. Chem. Soc. 2014, 136, 17561-17569; (g) Ethirajan, M.; Chen, Y.; Joshi, P.; Pandey, R. K. "The role of porphyrin chemistry in tumor imaging and photodynamic therapy", Chem. Soc. Rev. 2011, 40, 340-362; (h) Senge, M. O. "Stirring the porphyrin alphabet soup-functionalization reactions for porphyrins", Chem. Commun. 2011, 47, 1943-1960.

(4) (a) Kielmann, M.; Senge, M. O. "Molekulares Engineering freier Porphyrinbasen als Liganden - das N-H..X-Bindungsmotiv in Tetrapyrrolen", Angew. Chem. 2019, 131, 424-448; "Molecular Engineering of Free-Base Porphyrins as Ligands-The $\mathrm{N}-\mathrm{H}$...X Binding Motif in Tetrapyrroles", Angew. Chem. Int. Ed. 2019, 58, 418-441; (b) Kielmann, M.; Grover, N.; Kalisch, W. W.; Senge, M. O. "Incremental Introduction of Organocatalytic Activity into Conformationally Engineered Porphyrins", Eur. J. Org. Chem. 2019, 2448-2452; (c) Roucan, M.; Kielmann, M.; Connon, S. J.; Bernhard, S. S. R.; Senge, M. O. "Conformational control of nonplanar free base porphyrins: towards bifunctional catalysts of tunable basicity", Chem. Commun. 2018, 54, 26-29. (5) (a) Zhang, J.-X.; Chan, W.-L.; Xie, C.; Zhou, Y.; Chau, H.-F.; Maity, P.; Harrison, G. T.; Amassian, A.; Mohammed, O. F.; Tanner, P. A.; Wong, W.-K.; Wong, K.-L. "Impressive near-infrared brightness and singlet oxygen generation from strategic lanthanide-porphyrin double-decker complexes in aqueous solution", Light Sci. Appl. 2019, 8, No. 46; (b) Callaghan, S.; Senge, M. O. "The good, the bad, and the ugly - 
controlling singlet oxygen through design of photosensitizers and delivery systems for photodynamic therapy", Photochem. Photobiol. Sci. 2018, 17, 1490-1514; (c) Chen, Y.-Z.; Wang, Z. U.; Wang, H.; Lu, J.; Yu, S.-H.; Jiang, H.-L. "Singlet Oxygen-Engaged Selective Photo-Oxidation over Pt Nanocrystals/Porphyrinic MOF: The Roles of Photothermal Effect and Pt Electronic State", J. Am. Chem. Soc. 2017, 139, 20352044.

(6) Norvaiša, K.; Flanagan, K. J.; Gibbons, D.; Senge, M. O. "Konformativer Umbau von Porphyrinen als Rezeptoren mit schaltbaren N-H..X-Bindungsmodi", Angew. Chem. 2019, 131, 16705-16709; "Conformational Re-engineering of Porphyrins as Receptors with Switchable N-H $\cdots$ X-Type Binding Modes", Angew. Chem. Int. Ed. 2019, 58, 16553-16557.

(7) (a) Kielmann, M.; Flanagan, K. J.; Norvaiša, K.; Intrieri, D.; Senge, M. O. "Synthesis of a Family of Highly Substituted Porphyrin Thioethers via Nitro Displacement in 2,3,7,8,12,13,17,18-Octaethyl-5,10,15,20-tetranitroporphyrin", J. Org. Chem. 2017, 82, 5122-5134; (b) Meindl, A.; Plunkett, S.; Ryan, A. A.; Flanagan, K. J.; Callaghan, S.; Senge, M. O. "Comparative Synthetic Strategies for the Generation of 5,10- and 5,15-Substituted Push-Pull Porphyrins", Eur. J. Org. Chem. 2017, 3565-3583; (c) Hiroto, S.; Miyake, Y.; Shinokubo, H. "Synthesis and Functionalization of Porphyrins through Organometallic Methodologies", Chem. Rev. 2017, 117, 2910-3043.

(8) Nguyen, L. T.; Smith, K. M. "Syntheses of type-I porphyrins via monopyrrole tetramerization", Tetrahedron Lett. 1996, 37, 7177-7180.

(9) Nguyen, L. T.; Senge, M. O.; Smith, K. M. "One-pot synthesis of regiochemically pure porphyrins from two different pyrroles", Tetrahedron Lett. 1994, 35, 7581-7584. (10) Smith, K. M. "Porphyrins and bile pigments from brominated pyrromethenes", J. Chem. Soc., Perkin Trans. 1 1972, 1471-1475.

(11) Paine III, J. B.; Chang, C. K.; Dolphin, D. "The Synthesis of Porphyrins via Dipyrromethenes", Heterocycles 1997, 7, 831-838.

(12) Lim, C. K.; Rideout, J. M.; Wright, D. J. "Separation of porphyrin isomers by highperformance liquid chromatography", Biochem. J. 1983, 211, 435-438.

(13) Fyrestam, J.; Bjurshammar, N.; Paulsson, E.; Johannsen, A.; Östman, C. "Determination of porphyrins in oral bacteria by liquid chromatography electrospray ionization tandem mass spectrometry", Anal. Bioanal. Chem. 2015, 407, 7013-7023. 
(14) Taniguchi, M.; Lindsey, J. S. "Enumeration of Isomers of Substituted Tetrapyrrole Macrocycles: From Classical Problems in Biology to Modern Combinatorial Libraries" in Handbook of Porphyrin Science; Kadish, K. M.; Smith, K. M.; Guilard, R., Eds.; World Scientific: Singapore, 2012; Vol. 23, pp. 1-80.

(15) Chu, T. C.; Chu, E. J.-H. "Porphyrin Patterns in Different Types of Porphyria", Clin. Chem. 1967, 13, 371-387.

(16) Lindsey, J. S.; Schreiman, I. C.; Hsu, H. C.; Kearney, P. C.; Marguerettaz, A. M. "Rothemund and Adler-Longo reactions revisited: synthesis of tetraphenylporphyrins under equilibrium conditions", J. Org. Chem. 1987, 52, 827-836.

(17) Hursthouse, M. B.; Neidle, S. "The crystal structure of 5benzoyloxyoctaethylporphyrin. An example of a distorted porphyrin ring", J. Chem. Soc., Chem. Commun. 1972, 449-450.

(18) Senge, M. O. "Highly Substituted Porphyrins" in The Porphyrin Handbook; Kadish, K. M.; Smith, K. M.; Guilard, R., Eds.; Academic Press: New York, 2000; Vol. 1, pp. 239-348.

(19) (a) This figure was generated using Olex2;23b (b) Dolomanov, O. V.; Bourhis, L. J.; Gildea, R. J.; Howard, J. A. K.; Puschmann, H. "OLEX2: a complete structure solution, refinement and analysis program", J. Appl. Crystallogr. 2009, 42, 339-341.

(20) Sparks, L. D.; Medforth, C. J.; Park, M.-S.; Chamberlain, J. R.; Ondrias, M. R.; Senge, M. O.; Smith, K. M.; Shelnutt, J. A. "Metal dependence of the nonplanar distortion of octaalkyltetraphenylporphyrins", J. Am. Chem. Soc. 1993, 115, 581-592. (21) Oldenziel, O. H.; Van Leusen, D.; Van Leusen, A. M. "Chemistry of sulfonylmethyl isocyanides. 13. A general one-step synthesis of nitriles from ketones using tosylmethyl isocyanide. Introduction of a one-carbon unit", J. Org. Chem. 1977, 42, 3114-3118.

(22) Hirata, G.; Maeda, H. "Pyrrole-Based Anion-Responsive m-Electronic Molecules as Hydrogen-Bonding Catalysts", Org. Lett. 2018, 20, 2853-2856.

(23) Gale, P. A.; Sessler, J. L.; Camiolo, S. "Pyrrole- and Polypyrrole-Based Anion Receptors" in Enzyclopedia of Supramolecular Chemistry; Atwood, J. L.; Steed, J. W., Eds.; CRC Press: Boca Raton, FL, 2004; Vol. 2, pp. 1176-1185.

(24) An initial version of this work was deposited in ChemRxiv on March 29 $9^{\text {th }}, 2020$, Reference: Kielmann, M.; Flanagan, K.; Senge, M. "Targeted Synthesis of Regioisomerically Pure Dodecasubstituted Type I Porphyrins Through the Exploitation of Peri-Interactions." ChemRxiv 2020, preprint, 
https://doi.org/10.26434/chemrxiv.12045282.v1.

(25) Medforth, C. J.; Senge, M. O.; Forsyth, T. P.; Hobbs, J. D.; Shelnutt, J. A.; Smith, K. M. "Conformational Study of 2,3,5,7,8,12,13,15,17,18-Decaalkylporphyrins", Inorg. Chem. 1994, 33, 3865-3872.

(26) Watanabe, E.; Nishimura, S.; Ogoshi, H.; Yoshida, Z. "Orientation of electrophilic meso-substitution in metallooctaethylporphyrins" Tetrahedron 1975, 31, 1385-1390.

(27) Sugawara, S.; Kodama, M.; Hirata, Y.; Kojima, S.; Yamamoto, Y. "Synthesis and characterization of the most distorted $16 \pi$ porphyrin: $16 \pi$ octaisopropyltetraphenylporphyrin (OiPTPP)" J. Porphyrins Phthalocyanines 2011, 15, 1326-1334.

(28) van Leusen, A. M.; Siderius, H.; Hoogenboom, B. E.; van Leusen, D. "A new and simple synthesis of the pyrrole ring system from Michael acceptors and tosylmethylisocyanides", Tetrahedron Lett. 1972, 13, 5337-5340.

(29) Van Leusen, D.; Van Echten, E.; Van Leusen, A. M. "Chemistry of sulfonylmethyl isocyanides. 37. Synthesis of 3,4-disubstituted pyrroles bearing substituents of electron-withdrawing and/or electron-donating nature", J. Org. Chem. 1992, 57, 22452249. 